\title{
Common fixed point of multifunctions on partial metric spaces
}

\section{S Mohammad Ali Aleomraninejad ${ }^{1}$, Inci M Erhan ${ }^{2 *}$, Marwan A Kutbi ${ }^{3}$ and Masoumeh Shokouhnia ${ }^{4}$}

"Correspondence: inci.erhan@atilim.edu.tr

${ }^{2}$ Department of Mathematics, Atilim University, Incek, 06836, Ankara Full list of author information is available at the end of the article

\begin{abstract}
In this paper, some multifunctions on partial metric space are defined and common fixed points of such multifunctions are discussed. The results presented in the paper generalize some of the existing results in the literature. Several conclusions of the main results are given.
\end{abstract}

MSC: 47H10;54H10;46T99

Keywords: common fixed point; partial metric space; multifunction

\section{Introduction}

The notion of a partial metric space (PMS) was introduced by Matthews [1] in 1992 (see also [2]). The PMS is a generalization of the usual metric space in which $d(x, x)$ is no longer necessarily zero. Recently, many authors have focused on the PMS and its topological properties(see for example [3-15]). Partial metric spaces have extensive application potential in the research area of computer domains and semantics (see [15-18]).

A partial metric is a function $p: X \times X \rightarrow[0, \infty)$ satisfying the following conditions:

(a) $p(x, y)=p(y, x)$ (symmetry),

(b) $x=y \Longleftrightarrow p(x, x)=p(x, y)=p(y, y)$ (equality),

(c) $p(x, x) \leq p(x, y)$ (small self-distances),

(d) $p(x, y) \leq p(x, z)+p(y, z)-p(z, z)$ (triangularity),

for all $x, y, z \in X$. Then $(X, p)$ is called a partial metric space.

Each partial metric $p$ on $X$ generates a $T_{0}$ topology $\tau_{p}$ on $X$ with a base of the family of open $p$-balls $\left\{B_{p}(x, \varepsilon): x \in X, \varepsilon>0\right\}$, where

$$
B_{p}(x, \varepsilon)=\{y \in X: p(x, y)<p(x, x)+\varepsilon\},
$$

for all $x \in X$ and $\varepsilon>0$. For a partial metric $p$ on $X$, the function $d_{p}: X \times X \rightarrow[0, \infty)$ given by

$$
d_{p}(x, y)=2 p(x, y)-p(x, x)-p(y, y)
$$

is a (usual) metric on $X$. Another metric on $X$ induced by $p$ is defined in [19] as $d(x, y)=$ $p(x, y)$ whenever $x \neq y$ and $d(x, y)=0$ whenever $x=y$.

Some topological concepts and basic results on a PMS are defined as follows.

(C) 2015 Aleomraninejad et al. This article is distributed under the terms of the Creative Commons Attribution 4.0 International License (http://creativecommons.org/licenses/by/4.0/), which permits unrestricted use, distribution, and reproduction in any medium, provided you give appropriate credit to the original author(s) and the source, provide a link to the Creative Commons license, and indicate if changes were made. 
A sequence $\left\{x_{n}\right\}_{n \geq 1}$ in a PMS $(X, p)$ converges to $x \in X$ if and only if $p(x, x)=\lim _{n \rightarrow \infty} p(x$, $\left.x_{n}\right)$.

A sequence $\left\{x_{n}\right\}_{n \geq 1}$ is called a Cauchy sequence if and only if $\lim _{n, m \rightarrow \infty} p\left(x_{n}, x_{m}\right)$ exists and is finite.

A PMS $(X, p)$ is said to be complete whenever every Cauchy sequence $\left\{x_{n}\right\}_{n \geq 1}$ in $X$ converges to a point $x$ with respect to $\tau_{p}$, that is, $p(x, x)=\lim _{n, m \rightarrow \infty} p\left(x_{n}, x_{m}\right)$.

Lemma $1.1([3])$ Let $(X, p)$ be a partial metric space. Then:

(i) A sequence $\left\{x_{n}\right\}_{n \geq 1}$ is Cauchy in a PMS $(X, p)$ if and only if $\left\{x_{n}\right\}_{n \geq 1}$ is Cauchy in the metric space $\left(X, d_{p}\right)$.

(ii) A PMS $(X, p)$ is complete if and only if the metric space $\left(X, d_{p}\right)$ is complete. Moreover,

$$
\lim _{n \rightarrow \infty} d_{p}\left(x, x_{n}\right)=0 \Longleftrightarrow p(x, x)=\lim _{n \rightarrow \infty} p\left(x, x_{n}\right)=\lim _{n, m \rightarrow \infty} p\left(x_{n}, x_{m}\right) .
$$

An interesting property of partial metric spaces is the nonuniqueness of limits of sequences. To emphasize this property we consider the following example.

Example 1.1 Let $X=[0, \infty)$ and define a partial metric $p$ on $X$ as

$$
p(x, y)=\max \{x, y\}
$$

Consider the sequence $\left\{x_{n}\right\}=\left\{1+\frac{1}{n}\right\}$. Notice that

$$
\lim _{n \rightarrow \infty} p\left(x_{n}, 1\right)=\lim _{n \rightarrow \infty} \max \left\{1+\frac{1}{n}, 1\right\}=\lim _{n \rightarrow \infty} 1+\frac{1}{n}=1 .
$$

Also

$$
\lim _{n \rightarrow \infty} p\left(x_{n}, 2\right)=\lim _{n \rightarrow \infty} \max \left\{1+\frac{1}{n}, 2\right\}=\lim _{n \rightarrow \infty} 2=2 .
$$

Moreover, for any $a \geq 1$ we have

$$
\lim _{n \rightarrow \infty} p\left(x_{n}, a\right)=a
$$

In what follows, we introduce the notions, notations, and assumptions used in the discussion. Throughout this paper, we suppose that $(X, p)$ is a partial metric space. We denote the family of all nonempty subsets of $X$ by $2^{X}$, the family of all closed subsets of $X$ by $C(X)$ and the family of all closed and bounded subsets of $X$ by $C B(X)$. The partial Hausdorff distance $H_{p}$ on $C B(X)$ was introduced by Aydi et al. [20] as follows:

$$
H_{p}(A, B)=\max \left\{\sup _{a \in A} p(a, B), \sup _{b \in B} p(b, A)\right\}
$$

for all $A, B \in C B(X)$, where

$$
p(x, A)=\inf _{a \in A} p(x, a)
$$


Let $T: X \rightarrow 2^{X}$ be a multi-valued function (multifunction). We denote the set of fixed points of $T$ by $F(T)$, i.e.,

$$
F(T)=\{x \in X: x \in T x\} .
$$

Lemma 1.2 ([4]) Let $(X, p)$ be a partial metric space, $A \subseteq X$, and $x \in X$. Then $x \in \bar{A}$ if and only if $p(x, A)=p(x, x)$.

In 2012, Aydi et al. [20] proved the following fixed point theorem on partial metric space.

Theorem 1.3 Let $(X, p)$ be a complete partial metric space and $T: X \rightarrow C B(X)$ a multifunction. Suppose that there exist $k \in(0,1)$ such that

$$
H_{p}(T x, T y) \leq k p(x, y)
$$

for all $x, y \in X$. Then $T$ has a fixed point.

Some fixed point theorems for multifunctions on metric space are given next (see $[6,21,22])$.

Theorem 1.4 Let $(X, d)$ be a complete metric space and $T: X \rightarrow C B(X)$ a multifunction. Assume that there exists $r \in[0,1)$ such that

$$
\frac{1}{1+r} d(x, T x) \leq d(x, y) \quad \text { implies } \quad H(T x, T y) \leq r d(x, y),
$$

for all $x, y \in X$. Then $T$ has a fixed point.

Theorem 1.5 Let $(X, d)$ be a complete metric space and $T: X \rightarrow C(X)$ a multifunction. Assume that there exist $a, b, c \in[0,1)$ such that $a+b+c<1$ and

$$
\frac{(1-b-c)}{1+a} d(x, T x) \leq d(x, y)
$$

implies

$$
H(T x, T y) \leq a d(x, y)+b d(x, T x)+c d(y, T y)
$$

for all $x, y \in X$. Then $T$ has a fixed point.

The aim of this paper is to provide a new, more general condition for the multifunction $T$ which guarantees the existence of its fixed point. Our results generalize some of the existing ones.

In what follows, we consider two classes of functions, namely, $R_{1}$ and $R_{2}$ as defined below.

Definition 1.2 Let $R_{1}$ be the set of all continuous functions $g:[0, \infty)^{5} \rightarrow[0, \infty)$, satisfying the conditions:

(i) $g(t, t, t, 2 t, t)<t$, for all $t \in[0, \infty)$, 
(ii) $g$ is subhomogeneous, i.e., $g\left(\alpha x_{1}, \alpha x_{2}, \alpha x_{3}, \alpha x_{4}, \alpha x_{5}\right) \leq \alpha g\left(x_{1}, x_{2}, x_{3}, x_{4}, x_{5}\right)$, for all $\alpha \geq 0$,

(iii) if $x_{i}, y_{i} \in[0, \infty), x_{i} \leq y_{i}$ for $i=1, \ldots, 5$ we have $g\left(x_{1}, x_{2}, x_{3}, x_{4}, x_{5}\right) \leq g\left(y_{1}, y_{2}, y_{3}, y_{4}, y_{5}\right)$.

Let $R_{2}$ be the set of all continuous function $g:[0, \infty)^{5} \rightarrow[0, \infty)$ satisfying the following conditions:

(a) $g(t, t, t, t, t)<t$, for all $t \in[0, \infty)$,

(b) $g$ is subhomogeneous,

(c) if $x_{i}, y_{i} \in[0, \infty), x_{i} \leq y_{i}$ for $i=1, \ldots, 5$ we have $g\left(x_{1}, x_{2}, x_{3}, x_{4}, x_{5}\right) \leq g\left(y_{1}, y_{2}, y_{3}, y_{4}, x_{5}\right)$,

(d) for all $0 \leq a \leq x_{4}, g\left(x_{1}, x_{2}, x_{3}, x_{4}-a, a\right)=g\left(x_{1}, x_{2}, x_{3}, x_{4}, 0\right)$.

Remark 1.1 It is easy to see that if $g \in R_{1}$, then $g(1,1,1,2,1)=h \in(0,1)$. Indeed, if $g \in R_{1}$, the conditions (i) and (ii) give

$$
g(t, t, t, 2 t, t) \leq \operatorname{tg}(1,1,1,2,1)<t
$$

which implies $g(1,1,1,2,1)=h \in(0,1)$. In addition, if $g \in R_{2}$, then by a similar argument we observe that $g(1,1,1,1,1)=h \in(0,1)$

Examples of functions from both classes are given below.

Example 1.3 The function $g\left(x_{1}, x_{2}, x_{3}, x_{4}, x_{5}\right)=k \max \left\{x_{i}\right\}_{i=1}^{5}$ for $k \in\left(0, \frac{1}{2}\right)$ is in class $R_{1}$.

Example 1.4 The function $g\left(x_{1}, x_{2}, x_{3}, x_{4}, x_{5}\right)=k \max \left\{x_{1}, x_{2}, x_{3}, \frac{x_{4}+x_{5}}{2}\right\}$ for $k \in(0,1)$ belongs to $R_{2}$.

The following results are quite trivial.

Proposition 1.6 If $g \in R_{1}$ and $u, v \in[0, \infty)$ are such that

$$
u \leq \max \{g(v, u, v, u, v), g(v, u, v, v+u, v)\}
$$

then $u \leq h v$, where $h=g(1,1,1,2,1)$.

Proof From (iii) it is clear that $g(v, u, v, u, v) \leq g(v, u, v, v+u, v)$ and hence $u \leq \max \{g(v, u, v$, $u, v), g(v, u, v, v+u, v)\}=g(v, u, v, v+u, v)$. If $v<u$, then

$$
u \leq g(v, u, v, v+u, v) \leq g(u, u, u, 2 u, u) \leq u g(1,1,1,2,1)=h u<u
$$

which is a contradiction. Thus $u \leq v$, which implies

$$
u \leq g(v, u, v, v+u, v) \leq g(v, v, v, 2 v, v) \leq v g(1,1,1,2,1)=h v .
$$

Proposition 1.7 If $g \in R_{2}$ and $u, v \in[0, \infty)$ are such that

$$
u \leq \max \{g(v, u, v, u+v, 0), g(v, u, v, u, v)\}
$$

then $u \leq h v$ where $h=g(1,1,1,1,1)$. 
Proof Let $\max \{g(v, u, v, u+v, 0), g(v, u, v, u, v)\}=g(v, u, v, u+v, 0)$. If $v<u$, then (d) implies

$$
u \leq g(v, u, v, v+u, 0) \leq g(u, u, u, 2 u, 0) \leq u g(1,1,1,2,0)=u g(1,1,1,1,1)=h u<u,
$$

which is a contradiction. Thus $u \leq v$, and hence,

$$
u \leq g(v, u, v, v+u, 0) \leq g(v, v, v, 2 v, 0) \leq v g(1,1,1,2,0)=v g(1,1,1,1,1)=h v .
$$

Let $\max \{g(v, u, v, u+v, 0), g(v, u, v, u, v)\}=g(v, u, v, u, v)$. If $v<u$, then

$$
u \leq g(v, u, v, u, v) \leq g(u, u, u, u, u) \leq u g(1,1,1,1,1)=h u<u
$$

This contradicts our assumption, that is, we should have $u \leq v$. Then

$$
u \leq g(v, u, v, u, v) \leq g(v, v, v, v, v) \leq v g(1,1,1,1,1)=h v
$$

which completes the proof.

\section{Main results}

We state and proof our main results in this section.

Lemma 2.1 Let $(X, p)$ be a partial metric space and $T, S: X \rightarrow C(X)$ be two multifunctions. Suppose that there exist $\alpha \in(0, \infty)$ and $g \in R_{1} \cup R_{2}$ such that $\alpha p(x, T x) \leq p(x, y)$ or $\alpha p(y, S y) \leq p(x, y)$ implies

$$
H_{p}(T x, S y) \leq g(p(x, y), p(y, S y), p(x, T x), p(x, S y), p(y, T x))
$$

for all $x, y \in X$. Then for every $x \in F(T) \cup F(S)$ we have $p(x, x)=0$.

Proof Without loss of generality, we can suppose that $x \in T x$. Then $p(x, T x)=p(x, x)$ and hence

$$
\begin{aligned}
p(x, S x) & \leq H_{p}(T x, S x) \leq g(p(x, x), p(x, S x), p(x, T x), p(x, S x), p(x, T x)) \\
& \leq g(p(x, x), p(x, S x), p(x, x), p(x, S x), p(x, x)) .
\end{aligned}
$$

By using Proposition 1.6 if $g \in R_{1}$ or Proposition 1.7 if $g \in R_{2}$, we have

$$
p(x, x) \leq p(x, S x) \leq h p(x, x) .
$$

However, since $h<1$ we have $p(x, x)=0$.

Lemma 2.2 Let $(X, p)$ be a partial metric space and $T, S: X \rightarrow C(X)$ be two multifunctions. Suppose that there exist $\alpha \in(0, \infty)$ and $g \in R_{1} \cup R_{2}$ such that $\alpha p(x, T x) \leq p(x, y)$ or $\alpha p(y, S y) \leq p(x, y)$ implies

$$
H_{p}(T x, S y) \leq g(p(x, y), p(y, S y), p(x, T x), p(x, S y), p(y, T x))
$$

for all $x, y \in X$. Then $F(T)=F(S)$. 
Proof If $x \in T x$, then $p(x, T x)=p(x, x)=0$ by Lemma 2.1. Hence,

$$
\begin{aligned}
p(x, S x) & \leq H_{p}(T x, S x) \leq g(p(x, x), p(x, S x), p(x, T x), p(x, S x), p(x, T x)) \\
& \leq g(p(x, x), p(x, S x), p(x, x), p(x, S x), p(x, x)) \\
& \leq g(0, p(x, S x), 0, p(x, S x), 0) .
\end{aligned}
$$

By using Proposition 1.6 whenever $g \in R_{1}$ or Proposition 1.7 in case $g \in R_{2}$, we have $p(x, S x) \leq h 0=0$, and thus $x \in F(S)$. Thus, $F(T) \subseteq F(S)$. Similarly, we can show that $F(S) \subseteq F(T)$, which completes the proof.

In what follows, we state our main existence result.

Theorem 2.3 Let $(X, p)$ be a complete partial metric space and $T, S: X \rightarrow C(X)$ be two multifunctions. Suppose that there exist $g \in R_{1} \cup R_{2}$ and $\alpha \in(0,1)$, such that $\alpha(h+1) \leq 1$ where $h=g(1,1,1,2,1)$ if $g \in R_{1}$ and $h=g(1,1,1,1,1)$ if $g \in R_{2}$. Suppose also that $\alpha p(x, T x) \leq$ $p(x, y)$ or $\alpha p(y, S y) \leq p(x, y)$ implies

$$
H_{p}(T x, S y) \leq g(p(x, y), p(y, S y), p(x, T x), p(x, S y), p(y, T x))
$$

for all $x, y \in X$. Then $F(T)=F(S)$ and $F(T)$ is nonempty.

Proof By Lemma 2.2 we already have $F(T)=F(S)$. Fix arbitrary $1>r>h$ and $x_{0} \in X$ and choose $x_{1} \in T x_{0}$ such that $\alpha p\left(x_{0}, T x_{0}\right)<p\left(x_{0}, x_{1}\right)$. Then by the hypothesis of the theorem and condition (iii) or (c) in Definition 1.2, respectively, we have

$$
\begin{aligned}
p\left(x_{1}, S x_{1}\right) & \leq H_{p}\left(T x_{0}, S x_{1}\right) \leq g\left(p\left(x_{0}, x_{1}\right), p\left(x_{1}, S x_{1}\right), p\left(x_{0}, T x_{0}\right), p\left(x_{0}, S x_{1}\right), p\left(x_{1}, T x_{0}\right)\right) \\
& \leq g\left(p\left(x_{0}, x_{1}\right), p\left(x_{1}, S x_{1}\right), p\left(x_{0}, x_{1}\right), p\left(x_{0}, S x_{1}\right), p\left(x_{1}, x_{1}\right)\right) \\
& \leq g\left(p\left(x_{0}, x_{1}\right), p\left(x_{1}, S x_{1}\right), p\left(x_{0}, x_{1}\right), p\left(x_{0}, x_{1}\right)+p\left(x_{1}, S x_{1}\right)-p\left(x_{1}, x_{1}\right), p\left(x_{1}, x_{1}\right)\right) \\
& \leq g\left(p\left(x_{0}, x_{1}\right), p\left(x_{1}, S x_{1}\right), p\left(x_{0}, x_{1}\right), p\left(x_{0}, x_{1}\right)+p\left(x_{1}, S x_{1}\right), p\left(x_{1}, x_{1}\right)\right),
\end{aligned}
$$

where obviously $p\left(x_{0}, S x_{1}\right) \leq p\left(x_{0}, x_{1}\right)+p\left(x_{1}, S x_{1}\right)-p\left(x_{1}, x_{1}\right)$ due to triangle inequality in PMS. Suppose that $g \in R_{1}$. Since

$$
p\left(x_{1}, S x_{1}\right) \leq g\left(p\left(x_{0}, x_{1}\right), p\left(x_{1}, S x_{1}\right), p\left(x_{0}, x_{1}\right), p\left(x_{0}, x_{1}\right)+p\left(x_{1}, S x_{1}\right), p\left(x_{0}, x_{1}\right)\right)
$$

then, by Proposition 1.6, we have

$$
p\left(x_{1}, S x_{1}\right) \leq h p\left(x_{0}, x_{1}\right)<r p\left(x_{0}, x_{1}\right)
$$

Now let $g \in R_{2}$. Since

$$
p\left(x_{1}, S x_{1}\right) \leq g\left(p\left(x_{0}, x_{1}\right), p\left(x_{1}, S x_{1}\right), p\left(x_{0}, x_{1}\right), p\left(x_{0}, x_{1}\right)+p\left(x_{1}, S x_{1}\right)-p\left(x_{1}, x_{1}\right), p\left(x_{1}, x_{1}\right)\right),
$$

and obviously $0 \leq p\left(x_{1}, x_{1}\right) \leq p\left(x_{0}, x_{1}\right)+p\left(x_{1}, S x_{1}\right)$, we let $a=p\left(x_{1}, x_{1}\right)$ and employ condition (d) in Definition 1.2 to get

$$
p\left(x_{1}, S x_{1}\right) \leq g\left(p\left(x_{0}, x_{1}\right), p\left(x_{1}, S x_{1}\right), p\left(x_{0}, x_{1}\right), p\left(x_{0}, x_{1}\right)+p\left(x_{1}, S x_{1}\right), 0\right) .
$$


Now by Proposition 1.7, we have

$$
p\left(x_{1}, S x_{1}\right) \leq h p\left(x_{0}, x_{1}\right)<r p\left(x_{0}, x_{1}\right)
$$

We choose a number $\mu$ such that $\inf _{y \in S x_{1}} p\left(x_{1}, y\right)=p\left(x_{1}, S x_{1}\right)<\mu<r p\left(x_{0}, x_{1}\right)$. Thus there exists $x_{2} \in S x_{1}$ such that $p\left(x_{1}, x_{2}\right)<\mu<r p\left(x_{0}, x_{1}\right)$. Since $\alpha p\left(x_{1}, S x_{1}\right)<p\left(x_{1}, x_{2}\right)$, by using (14) and the properties of the function $g$ we have

$$
\begin{aligned}
p\left(x_{2}, T x_{2}\right) & \leq H_{p}\left(S x_{1}, T x_{2}\right) \leq g\left(p\left(x_{1}, x_{2}\right), p\left(x_{2}, T x_{2}\right), p\left(x_{1}, S x_{1}\right), p\left(x_{1}, T x_{2}\right), p\left(x_{2}, S x_{1}\right)\right) \\
& \leq g\left(p\left(x_{1}, x_{2}\right), p\left(x_{2}, T x_{2}\right), p\left(x_{1}, x_{2}\right), p\left(x_{1}, x_{2}\right)+p\left(x_{2}, T x_{2}\right)-p\left(x_{2}, x_{2}\right), p\left(x_{2}, x_{2}\right)\right) \\
& \leq g\left(p\left(x_{1}, x_{2}\right), p\left(x_{2}, T x_{2}\right), p\left(x_{1}, x_{2}\right), p\left(x_{1}, x_{2}\right)+p\left(x_{2}, T x_{2}\right), p\left(x_{1}, x_{2}\right)\right) .
\end{aligned}
$$

Now, if $g \in R_{1}$, using Proposition 1.6 and mimicking the proof of (15) we obtain

$$
p\left(x_{2}, T x_{2}\right) \leq h p\left(x_{1}, x_{2}\right)<r p\left(x_{1}, x_{2}\right)
$$

If $g \in R_{2}$, letting $a=p\left(x_{2}, x_{2}\right)$ we get

$$
\begin{aligned}
p\left(x_{2}, T x_{2}\right) & \leq g\left(p\left(x_{1}, x_{2}\right), p\left(x_{2}, T x_{2}\right), p\left(x_{1}, x_{2}\right), p\left(x_{1}, x_{2}\right)+p\left(x_{2}, T x_{2}\right)-p\left(x_{2}, x_{2}\right), p\left(x_{2}, x_{2}\right)\right) \\
& \leq g\left(p\left(x_{1}, x_{2}\right), p\left(x_{2}, T x_{2}\right), p\left(x_{1}, x_{2}\right), p\left(x_{1}, x_{2}\right)+p\left(x_{2}, T x_{2}\right), 0\right)
\end{aligned}
$$

and hence Proposition 1.7 yields

$$
p\left(x_{2}, T x_{2}\right) \leq h p\left(x_{1}, x_{2}\right)<r p\left(x_{1}, x_{2}\right)
$$

In a similar way, we can choose $x_{3} \in T x_{2}$ such that

$$
p\left(x_{2}, x_{3}\right)<r p\left(x_{1}, x_{2}\right)<r^{2} p\left(x_{0}, x_{1}\right) .
$$

By continuing this process, we obtain a sequence $\left\{x_{n}\right\}_{n \geq 1}$ in $X$ such that

$$
x_{2 n-1} \in T x_{2 n-2}, \quad x_{2 n} \in S x_{2 n-1},
$$

which satisfies

$$
p\left(x_{n}, x_{n+1}\right) \leq r^{n} p\left(x_{0}, x_{1}\right) .
$$

Then $p\left(x_{2 n}, T x_{2 n}\right) \leq h p\left(x_{2 n-1}, x_{2 n}\right)$ and $p\left(x_{2 n-1}, S x_{2 n-1}\right) \leq h p\left(x_{2 n-2}, x_{2 n-1}\right)$.

If $x_{m}=x_{m+1}$ for some $m \geq 1$ where $m=2 k$, then

$$
p\left(x_{2 k}, x_{2 k}\right) \leq p\left(x_{2 k}, T x_{2 k}\right) \leq p\left(x_{2 k}, x_{2 k+1}\right)=p\left(x_{2 k}, x_{2 k}\right)
$$

so $p\left(x_{2 k}, T x_{2 k}\right)=p\left(x_{2 k}, x_{2 k}\right)$, and hence $x_{2 k} \in T x_{2 k}$. Thus $T$ and $S$ have a fixed point. If $m=$ $2 k+1$ in a similar way we find that $T$ and $S$ have a fixed point. 
Suppose that $x_{n} \neq x_{n+1}$, for all $n \geq 1$. Repeated application of the triangle inequality implies

$$
\begin{aligned}
p\left(x_{n}, x_{n+m}\right) & \leq p\left(x_{n}, x_{n+1}\right)+p\left(x_{n+1}, x_{n+2}\right)+\cdots+p\left(x_{n+m-1}, x_{n+m}\right) \\
& \leq r^{n} p\left(x_{0}, x_{1}\right)+r^{n+1} p\left(x_{0}, x_{1}\right)+\cdots+r^{n+m-1} p\left(x_{0}, x_{1}\right) \\
& \leq r^{n} p\left(x_{0}, x_{1}\right)\left(1+r+r^{2}+\cdots+r^{m-1}\right) \\
& \leq \frac{r^{n}}{1-r} p\left(x_{0}, x_{1}\right) .
\end{aligned}
$$

Then we get

$$
\lim _{n \rightarrow \infty} p\left(x_{n}, x_{n+m}\right) \rightarrow 0
$$

and hence $\left\{x_{n}\right\}_{n \geq 1}$ is a Cauchy sequence in $(X, p)$. Regarding Lemma 1.1, $\left\{x_{n}\right\}_{n \geq 1}$ is also a Cauchy sequence in $\left(X, d_{p}\right)$. Since $(X, p)$ is a complete partial metric space, by Lemma 1.1, $\left(X, d_{p}\right)$ is also complete. Thus $\left\{x_{n}\right\}_{n \geq 1}$ converges to a limit, say, $x \in X$, that is,

$$
\lim _{n \rightarrow \infty} d_{p}\left(x_{n}, x\right)=0
$$

Notice that Lemma 1.1 yields

$$
p(x, x)=\lim _{n \rightarrow \infty} p\left(x_{n}, x\right)=\lim _{n, m \rightarrow \infty} p\left(x_{n}, x_{m}\right)=0 .
$$

Now, we claim that for each $n \geq 1$ one of the relations

$$
\alpha p\left(x_{2 n}, T x_{2 n}\right) \leq p\left(x_{2 n}, x\right) \quad \text { or } \quad \alpha p\left(x_{2 n+1}, S x_{2 n+1}\right) \leq p\left(x_{2 n+1}, x\right)
$$

holds. If for some $n \geq 1$ we have $\alpha p\left(x_{2 n}, T x_{2 n}\right)>p\left(x_{2 n}, x\right)$ and $\alpha p\left(x_{2 n+1}, S x_{2 n+1}\right)>p\left(x_{2 n+1}, x\right)$ then

$$
\begin{aligned}
p\left(x_{2 n}, x_{2 n+1}\right) & \leq p\left(x_{2 n}, x\right)+p\left(x, x_{2 n+1}\right) \\
& <\alpha p\left(x_{2 n}, T x_{2 n}\right)+\alpha p\left(x_{2 n+1}, S x_{2 n+1}\right) \\
& \leq \alpha p\left(x_{2 n}, x_{2 n+1}\right)+\alpha h p\left(x_{2 n}, x_{2 n+1}\right) .
\end{aligned}
$$

This results in $\alpha(h+1)>1$, which contradicts the initial assumption. Hence, our claim is proved. Observe that by the assumption of the theorem, for each $n \geq 1$ we have either

$$
H_{p}\left(T x_{2 n}, S x\right) \leq g\left(p\left(x_{2 n}, x\right), p(x, S x), p\left(x_{2 n}, T x_{2 n}\right), p\left(x_{2 n}, S x\right), p\left(x, T x_{2 n}\right)\right)
$$

or

$$
H_{p}\left(S x_{2 n+1}, T x\right) \leq g\left(p\left(x_{2 n+1}, x\right), p(x, T x), p\left(x_{2 n+1}, S x_{2 n+1}\right), p\left(x_{2 n+1}, T x\right), p\left(x, S x_{2 n+1}\right)\right) .
$$

Therefore, one of the following cases holds. 
Case (i). There exists an infinite subset $I \subseteq \mathbb{N}$ such that

$$
\begin{aligned}
p\left(x_{2 n+1}, S x\right) & \leq H_{p}\left(T x_{2 n}, S x\right) \\
& \leq g\left(p\left(x_{2 n}, x\right), p(x, S x), p\left(x_{2 n}, T x_{2 n}\right), p\left(x_{2 n}, S x\right), p\left(x, T x_{2 n}\right)\right)
\end{aligned}
$$

for all $n \in I$.

Case (ii). There exists an infinite subset $J \subseteq \mathbb{N}$ such that

$$
\begin{aligned}
p\left(x_{2 n+2}, T x\right) & \leq H_{p}\left(S x_{2 n+1}, T x\right) \\
& \leq g\left(p\left(x_{2 n+1}, x\right), p(x, T x), p\left(x_{2 n+1}, S x_{2 n+1}\right), p\left(x_{2 n+1}, T x\right), p\left(x, S x_{2 n+1}\right)\right),
\end{aligned}
$$

for all $n \in J$.

In Case (i), we get

$$
\begin{aligned}
p(x, S x) \leq & p\left(x, x_{2 n+1}\right)+p\left(x_{2 n+1}, S x\right) \\
\leq & p\left(x, x_{2 n+1}\right)+g\left(p\left(x_{2 n}, x\right), p(x, S x), p\left(x_{2 n}, T x_{2 n}\right), p\left(x_{2 n}, S x\right), p\left(x, T x_{2 n}\right)\right) \\
\leq & p\left(x, x_{2 n+1}\right) \\
& +g\left(p\left(x_{2 n}, x\right), p(x, S x), p\left(x_{2 n}, x_{2 n+1}\right), p\left(x_{2 n}, x\right)+p(x, S x)-p(x, x), p\left(x, x_{2 n+1}\right)\right),
\end{aligned}
$$

for all $n \in I$. Continuity of $g$ implies

$$
p(x, S x) \leq g(0, p(x, S x), 0,0+p(x, S x)-0,0)
$$

Now by using Propositions 1.6 and 1.7, we have $p(x, S x)=0$, and thus $x \in S x$.

In Case (ii), we have

$$
\begin{aligned}
p(x, T x) \leq & p\left(x, x_{2 n+2}\right)+p\left(x_{2 n+2}, T x\right) \\
\leq & p\left(x, x_{2 n+2}\right)+g\left(p\left(x_{2 n+1}, x\right), p(x, T x), p\left(x_{2 n+1}, S x_{2 n+1}\right), p\left(x_{2 n+1}, T x\right), p\left(x, S x_{2 n+1}\right)\right) \\
\leq & p\left(x, x_{2 n+2}\right) \\
& +g\left(p\left(x_{2 n+1}, x\right), p(x, T x), p\left(x_{2 n+1}, x_{2 n+2}\right),\right. \\
& \left.p\left(x_{2 n+1}, x\right)+p(x, T x)-p(x, x), p\left(x, x_{2 n+2}\right)\right),
\end{aligned}
$$

for all $n \in J$. Since $g$ is continuous, we obtain

$$
p(x, T x) \leq g(0, p(x, T x), 0,0+p(x, T x)-0,0) .
$$

Again, by using Propositions 1.6 and 1.7, we have $p(x, T x)=0$, which gives $x \in T x$. This completes the proof.

The following results are consequences of Theorem 2.3.

Theorem 2.4 Let $(X, p)$ be a complete partial metric space and $T: X \rightarrow C(X)$ be a multifunction. Suppose that there exist $\alpha \in(0,1)$ and $g \in R$ with $h=g(1,1,1,2,0)$ such that 
$\alpha(h+1) \leq 1$ and $\alpha p(x, T x) \leq p(x, y)$ implies

$$
H_{p}(T x, T y) \leq g(p(x, y), p(y, T y), p(x, T x), p(x, T y), p(y, T x))
$$

for all $x, y \in X$. Then $T$ has a fixed point.

Corollary 2.5 Theorem 1.3 introduced in [20] is a special case of Theorem 2.4.

Proof Define $g \in R_{1}$ by $g\left(x_{1}, x_{2}, x_{3}, x_{4}, x_{5}\right)=k x_{1}$.

Now we provide the partial metric versions of Theorems 1.4 and 1.5.

Theorem 2.6 Let $(X, p)$ be a complete partial metric space and $T: X \rightarrow C B(X)$ be a multifunction. Assume that there exists $r \in[0,1)$ such that

$$
\frac{1}{1+r} p(x, T x) \leq p(x, y) \quad \text { implies } \quad H_{p}(T x, T y) \leq r p(x, y)
$$

for all $x, y \in X$. Then $T$ has a fixed point.

Proof Define $g \in R_{1}$ by $g\left(x_{1}, x_{2}, x_{3}, x_{4}, x_{5}\right)=r x_{1}$. Let $\alpha=\frac{1}{1+r}$. Since $h=r$ and $\alpha(1+h) \leq 1$, by using Theorem 2.3, $T$ has a fixed point.

Theorem 2.7 Let $(X, p)$ be a complete partial metric space and $T: X \rightarrow C(X)$ be a multifunction. Assume that there exist $a, b, c \in[0,1)$ such that $a+b+c<1$ and

$$
\begin{aligned}
& \frac{(1-b-c)}{1+a} p(x, T x) \leq p(x, y) \quad \text { implies } \\
& H_{p}(T x, T y) \leq a p(x, y)+b p(x, T x)+c p(y, T y) .
\end{aligned}
$$

Then T has a fixed point.

Proof Define $g \in R_{1}$ by $g\left(x_{1}, x_{2}, x_{3}, x_{4}, x_{5}\right)=a x_{1}+c x_{2}+b x_{3}$. Let $\alpha=\frac{1-b-c}{1+a}$. Since $h=a+b+c$ and $\alpha(1+h) \leq 1$, by Theorem $2.3, T$ has a fixed point.

Competing interests

The authors declare that they have no competing interests.

Authors' contributions

All authors contributed equally to this work. All authors read and approved the final manuscript.

\section{Author details}

'Department of Mathematics, Qom University of Technology, Qom, Iran. ${ }^{2}$ Department of Mathematics, Atilim University, Incek, 06836, Ankara. ${ }^{3}$ Department of Mathematics, King Abdulaziz University, P.O. Box 80203, Jeddah, 21589, Saudi Arabia. ${ }^{4}$ Department of Mathematics, Alzahra University, Tehran, Iran.

\section{Acknowledgements}

The authors would like to thank referees for their useful comments and suggestions for the improvement of the paper. The third author gratefully acknowledges the support from the Deanship of Scientific Research (DSR) at King Abdulaziz University (KAU) in Jeddah, Kingdom of Saudi Arabia during this research. 


\section{References}

1. Matthews, SG: Partial metric topology. Research Report 212, Dept. of Computer Science, University of Warwick (1992)

2. Matthews, SG: Partial metric topology. In: Proc. 8th Summer Conference on General Topology and Applications. Annals of the New York Academy of Sciences, vol. 728, pp. 183-197 (1994)

3. Abdeljawad, T, Karapınar, E, Tas, K: Existence and uniqueness of a common fixed point on partial metric spaces. Appl. Math. Lett. 24, 1900-1904 (2011)

4. Altun, I, Sola, F, Şimşek, H: Generalized contractions on partial metric spaces. Topol. Appl. 157, 2778-2785 (2010)

5. Karapınar, E: Some fixed point theorems on the class of comparable partial metric spaces. Appl. Gen. Topol. 12(2), 187-192 (2011)

6. Aleomraninejad, SMA, Rezapour, S, Shahzad, N: On fixed point generalizations of Suzuki's method. Appl. Math. Lett. 24, 1037-1040 (2011)

7. Oltra, S, Valero, O: Banach's fixed point theorem for partial metric spaces. Rend. Ist. Mat. Univ. Trieste 36, 17-26 (2004)

8. Valero, O: On Banach fixed point theorems for partial metric spaces. Appl. Gen. Topol. 6, 229-240 (2005)

9. Altun, I, Erduran, A: Fixed point theorems for monotone mappings on partial metric spaces. Fixed Point Theory Appl. 2011, Article ID 508730 (2011)

10. Romaguera, S: A Kirk type characterization of completeness for partial metric spaces. Fixed Point Theory Appl. 2010 Article ID 493298 (2010)

11. Aydi, H, Karapınar, E: A Meir-Keeler common type fixed point theorem on partial metric spaces. Fixed Point Theory Appl. 2012, Article ID 26 (2012)

12. Karapınar, E: Generalization of Caristi-Kirk's theorems on partial metric spaces. Fixed Point Theory Appl. 2011, Article ID 4 (2011)

13. Karapınar, E, Erhan, IM, YIldız, UA: Fixed point theorem for cyclic maps on partial metric spaces. Appl. Math. Inf. Sci. 6 239-244 (2012)

14. Karapınar, E, Chi, KP, Thanh, TD: A generalization of Ćirić quasicontractions. Abstr. Appl. Anal. 2012, Article ID 518734 (2012)

15. Romaguera, S, Schellekens, M: Weightable quasi-metric semigroup and semilattices. Electron. Notes Theor. Comput. Sci. 40, 347-358 (2001)

16. Kopperman, R, Matthews, SG, Pajoohesh, H: What do partial metric represent? In: Spatial Representation: Discrete vs. Continuous Computational Models. Dagstuhl Seminar Proceedings, vol. 4351. Internationales Begegnungs und Forschungszentrum fur Informatik (IBFI), Schloss Dagstuhl, Wadern (2005)

17. Kunzi, HPA, Pajoohesh, H, Schellekens, MP: Partial quasi-metrics. Theor. Comput. Sci. 365(3), 237-246 (2006)

18. Schellekens, M: A characterization of partial metrizability: domains are quantifiable. Theor. Comput. Sci. 305(1-3), 409-432 (2003)

19. Haghi, RH, Rezapour, S, Shahzad, N: Be careful on partial metric fixed point results. Topol. Appl. 160, 450-454 (2013)

20. Aydi, H, Abbas, M, Vetro, C: Partial Hausdorff metric and Nadler's fixed point theorem on partial metric spaces. Topol. Appl. 159, 3234-3242 (2012)

21. Choudhury, BS, Konar, $\mathrm{P}$, Rhoades, BE, Metiya, N: Fixed point theorems for generalized weakly contractive mappings. Nonlinear Anal. 74, 2116-2126 (2011)

22. Dhompongsa, S, Yingtaweesittikul, H: Fixed point for multivalued mappings and the metric completeness. Fixed Point Theory Appl. 2009, Article ID 972395 (2009)

\section{Submit your manuscript to a SpringerOpen ${ }^{\circ}$ journal and benefit from:}

- Convenient online submission

Rigorous peer review

- Immediate publication on acceptance

- Open access: articles freely available online

- High visibility within the field

- Retaining the copyright to your article 